\title{
Mathematics Teachers' Pedagogical Content Knowledge Involving the Relationships between Perimeter and Area
}

\author{
By Demet Deniz Yilmaz * \& Betül Küçük Demir ${ }^{ \pm}$
}

\begin{abstract}
This study aims to investigate and compare mathematics teachers' knowledge of pedagogical content, knowledge of students' understanding and knowledge of instructional strategies, subcomponents of pedagogical content knowledge, student errors in the relationship between perimeter and areas in rectangles, squares, and parallelograms. 10 pre-secondary school in-service mathematics teachers and 10 prospective mathematics teachers participated in the study. The qualitative case research approach was used. To collect the data, an interview form consisting of four questions showing student errors related to perimeter and area was prepared. The participants were asked to comment on the questions given in the form, and their answers were recorded. Later, they were asked to write down their answers to these questions. According to the outcomes, there is a lack of knowledge of students' understanding and knowledge of instructional strategies, which are the subcomponents of the pedagogical content knowledge of prospective mathematics teachers. Moreover, prospective teachers are found to be incompetent as regards the necessary mathematical subject matter knowledge. To prevent difficulties, when the concepts of perimeter and area are taught, instead of giving formulae initially, concrete materials or real-life examples about these concepts should be provided.
\end{abstract}

Keywords: pedagogical content knowledge, perimeter, area, mathematics teachers, prospective mathematics teachers.

\section{Introduction}

The topics of perimeter and area are the basic subjects for the competence of elementary school teachers (Reinke, 1997). However, these are confusing topics as both involve measurement, their formulae are taught almost simultaneously to students, and memorizing these formulae may be confusing (Van de Walle, Karp, \& Bay-Williams, 2014). This is confusing for both students and teachers. Some studies show that teachers often confuse the concepts of perimeter and area because they assume a constant relationship between area and perimeter (Baturo \& Nason, 1996; De Sousa, Gusmão, Font, \& Lando, 2020; Yeo, 2008). According to several studies, prospective teachers have also been found to be incompetent in comprehending concepts, their knowledge is based on rules and formulae, they have some difficulties in explaining what these formulae are for, and they focus on using formulae rather than activities designed to reinforce concepts (Baturo \& Nason, 1996; Berenson et al., 1997; Livy, Muir, \& Maher, 2012; Menon, 1998; Reinke, 1997; Runnalls \& Hong, 2019). According to Zacharos (2006), using formulae first while measuring area leads to misconceptions about area measurement and makes it difficult to interpret the physical meaning of the numerical representation of the area. According to Baturo and Nason (1996),

\footnotetext{
*Assistant Professor, Faculty of Education, Mus Alparslan University, Turkey.

${ }^{ \pm}$Assistant Professor, Faculty of Education Bayburt University, Turkey.
} 
many prospective teachers are devoid of concrete measurement experiences such as covering the surface area with measurement units, and they think of area as multiplication of width by length. This situation shows that the difficulties that prospective teachers face may stem from their learning experiences at school (Baturo \& Nason, 1996).

Difficulties regarding area and perimeter are usually related to conservation of area and perimeter and using inappropriate units while calculating them (not using square units while reporting area measurements) (Baturo \& Nason, 1996; Guner \& Akyuz, 2017; Ma, 1999; Murphy, 2012; Yeo, 2008). It is also generally thought that two rectangles with the same area must have the same perimeter (Van de Walle, Karp, \& Bay-Williams, 2014). However, this is not always valid. Similarly, two rectangles with the same perimeter measurements cannot be expected to have the same area, and this situation is not also limited to rectangles (Van de Walle, Karp, \& Bay-Williams, 2014).

In fact, confusion of the topics of area and perimeter, how teachers teach these topics, and how they react to these errors are the basis of problems experienced by students related to area and perimeter. This is because teachers who have not exactly understood mathematical concepts cannot be expected to explain these concepts. What are more, teachers who have a good command of the subject matter but cannot present the topic in a way that students can understand also experience similar problems (Yeo, 2008). The main reason for this is that teachers use different types of knowledge for teaching mathematics (Rowland, Turner, Thwaites, \& Huckstep, 2009; Shulman, 1987). They must not only be equipped with a good command of the subject matter but also have the knowledge of how to present it to enhance student comprehension in the most effective way and detect students' learning difficulties and mistakes (Gökkurt, 2014). These pieces of knowledge were first termed by Shulman (1986a) as pedagogical content knowledge. The concept of pedagogical content knowledge is used to express teachers' interpretations and transformations of subject-matter knowledge to support student learning. It especially involves understanding students' learning difficulties and prejudices (Van Driel, Verloop, \& De Vos, 1998), and it represents certain strategies and approaches of the teacher while conveying mathematical knowledge to students (Van de Walle, Karp, \& Bay-Williams, 2014).

Pedagogical content knowledge may be used effectively and flexibly during the interaction process between students and teachers. Teachers' actions while dealing with subjects largely depend on their pedagogical content knowledge (Van Driel, Verloop, \& De Vos, 1998). Shulman (1986b) specified teachers' knowledge as subject matter knowledge, pedagogical content knowledge, and curriculum knowledge. Shulman (1987) also pointed out that pedagogical content knowledge has two components. These are the knowledge of representations, which involves instructional strategies that are used by teachers to make subject matters understandable to students, and the knowledge of students' learning difficulties, which is related to their misconceptions about subjects (Hume, 2011). Instructional strategies are the way subject matters are taught (Van Driel, Jong, \& Verloop, 2002), as well as representations in the forms of pictures, analogies, and explanations to make a subject matter more comprehensible for students 
(Shulman, 1987). Knowledge of students' understanding, on the other hand, comprises the knowledge related to student misconceptions, naive ideas obtained through the interpretation of prior learning experiences, and preconceived ideas about the subject matter (Shulman, 1987).

Looking at difficulties related to area and perimeter, it may be seen that these problems are not only experienced by students at schools (Livy, Muir, \& Maher, 2012). In this case, inevitably, students often have misconceptions about area and perimeter. To cope with this situation, therefore, teachers should not only try to teach students in a way that avoids misunderstandings, but they should also have approaches to deal with the misconceptions that arise (Chick \& Baker, 2005). On the other hand, prospective teachers with a limited understanding of area may fail to help children develop this notion because a prospective teacher's understanding of the nature of the area is seen as a key concept in their style of teaching (Murphy, 2012). To solve the difficulties experienced in the concepts of area and perimeter, it is important to raise prospective and in-service teachers' awareness of pedagogical content knowledge related to these topics. For this reason, this study aimed to investigate student errors in terms of the relationship between area and perimeter in rectangles, squares, and parallelograms regarding mathematics teachers' and prospective mathematic teachers' in accordance with their knowledge of students' understanding and knowledge of instructional strategies. This study will also reveal how the teaching experiences and mathematical backgrounds of in-service teachers and prospective teachers affect the knowledge of students' understanding and knowledge of instructional strategies.

\section{Methodology}

\section{Research Model}

One of the approaches of qualitative research, a case study, was employed in this study. Since the objective was to examine the participants' voice recordings on their explanations and answers to questions in a detailed way, a case study approach was used. Case studies serve to discover a phenomenon about which little is known or to examine it thoroughly. This approach owes its power to the researcher's ability to investigate the case in-depth and in detailed manner (Arthur, Waring, Coe, \& Hedges, 2017). In this study, the aim is to investigate mathematics teachers' and prospective mathematics teachers' pedagogical content knowledge, their knowledge of students' understanding and knowledge of instructional strategies in relation to student errors in the relationship between perimeter and area in rectangles, squares and parallelograms in a detailed way.

\section{Participants}

This study was carried out with 10 pre-secondary school in-service mathematics teachers (years of service between 5 and 7 years) and 10 prospective mathematics teachers who were senior students. The reason why prospective 
teachers were chosen from among senior students was that they were assumed as knowledgeable and competent enough in the subject matter. The in-service and prospective teachers who participated in the study were chosen voluntarily. While choosing the participants, convenience sampling, which is a purposive sampling method, was utilized. The names of the in-service teachers and prospective teachers that took part in the study are kept confidential. While the in-service teachers are coded as T1, T2, T3, etc., the prospective teachers are coded as P1, $\mathrm{P} 2, \mathrm{P} 3$, etc.

\section{Data Collection}

As a means of data collection, an interview form involving four questions about student errors in perimeter and area was prepared. The interview schedule was in such a way that it could be possible to determine the participants' knowledge of students' understanding and knowledge of instructional strategies. If the interview questions are examined, it may be seen that the first question was prepared by inspiration from Ma's (1999) study, while the second and third ones were inspired by Tan Şişman and Aksu's study (2009). The fourth question was prepared by inspiration from Murphy's (2012) question, which had been adapted from the question in Tierney, Boyd, and Davis's study (1990). The first question was prepared to identify knowledge of students' understanding and knowledge of instructional strategies about changes in the perimeter and area of a rectangle. The second question aimed to test the notion of the variability of perimeter, while the third one sought to learn about knowledge of students' understanding and knowledge of instructional strategies related to area conservation. The last question was prepared to identify knowledge of students' understanding and knowledge of instructional strategies on the variability of the area and perimeter of parallelograms and rectangles. The reasons why the rectangle, the square, and the parallelogram were chosen for this study were that these are the topics students are taught on the pre-secondary school level. Moreover, they are interconnected, and there are very few studies in the literature dealing with the square, the rectangle and the parallelogram at the same time. The participants were given an interview form that includes a group of student errors. The participants' views were recorded by a voice recorder, and they were asked to write down their answers to the questions. Similar to the case in the study by Gökkurt, Şahin, Soylu, and Doğan (2015), by looking into whether the participants were able to detect student errors or not, the researchers tried to determine their knowledge of students' understanding, and by taking their suggestions on how to correct student errors into consideration, they tried to determine the participants' knowledge of instructional strategies.

\section{Data Analysis}

Descriptive analysis techniques were employed to analyze data. In the descriptive analysis, data are summarised and interpreted according to previously set themes (Yıldırım \& Şimşek, 2013). For descriptive analysis, the framework prepared by Gökkurt, Şahin, Soylu, and Soylu (2013) was used after making some 
alterations as a result of the inconsistency of the present data with the codes they used. The reason why the researchers benefited from their framework was that, while forming this framework, Gökkurt, Sahin, Soylu, and Soylu (2013) formed certain draft themes and codes after collecting prospective teachers' written answers, and they reorganized them after reading these answers repeatedly. Later, they consulted an expert on whether they were comprehensible in terms of their validity, and consequently, after certain corrections, they made them clear and understandable enough for the reader. The framework created by Gökkurt, Sahin, Soylu, and Soylu (2013) was not used as the codes and themes in that study did not correspond to those in this one. Instead, in the light of the data obtained, new codes and themes were formed. An expert was consulted to check the validity of these codes and themes. In this study, the collected data were coded, and re-coded at different times by different researchers to increase reliability. These codes and categories are given in Table 1 . The reliability percentage of the data coded according to the codes and categories in Table 1 was found to be $87 \%$. For the uncommon codes, the researchers came together and negotiated. Uncompromised codes were removed, and some codes were changed. To ensure the validity of the study, the procedures in the study were described in a detailed way, and another researcher who is an expert in pedagogical content knowledge was consulted in the processes of preparation of the data collection tools and data analysis. Moreover, the researchers presented how they reached the results in a clear, understandable, and consistent way. In the section related to the codes obtained, direct quotes taken from the participants' answers are given. To ensure reliability, on the other hand, the researchers made sure that the results obtained were consistent with the data, and they explained the processes of data collection, forming categories and codes and analysis of these in a detailed way.

Table 1. Codes and Categories

\begin{tabular}{|l|l|}
\hline Category & \multicolumn{1}{c|}{ Code } \\
\hline \multirow{4}{*}{ Finding the error correctly } & $\begin{array}{l}\text { Finding the error correctly and recommending a partially correct } \\
\text { solution }\end{array}$ \\
\cline { 2 - 3 } Not finding the error & Finding the error correctly and recommending a correct solution \\
\hline \multirow{5}{*}{$\begin{array}{l}\text { correctly } \\
\text { Finding the error partially } \\
\text { correctly }\end{array}$} & Fo answer \\
\cline { 2 - 3 } & $\begin{array}{l}\text { Finding the error incorrectly and no solution recommendations } \\
\text { solution }\end{array}$ \\
\cline { 2 - 3 } & Finding the error incorrectly and recommending an incorrect solution \\
\cline { 2 - 3 } & $\begin{array}{l}\text { Finding the error partially correctly and recommending a partially } \\
\text { correct solution }\end{array}$ \\
\hline
\end{tabular}




\section{Results}

In this section, the in-service and prospective mathematics teachers' ability to detect student errors, which is their knowledge of students' understanding, and their suggestions, methods, techniques, and strategies to correct these errors, which are called knowledge of instructional strategies, are investigated by looking into the explanations of the participants and their written solutions. The obtained data are presented with direct quotes, and they are also given in the tables featuring categories, codes, and frequencies. Table 2 shows the code, category and frequency information of the prospective teachers' answers to the first question.

Table 2. Prospective Teachers' Answers to the First Question

\begin{tabular}{|l|c|c|c|}
\hline \multirow{2}{*}{ Category } & Code & $\begin{array}{c}\text { Prospective } \\
\text { Teachers }\end{array}$ & Frequency \\
\hline \multirow{2}{*}{$\begin{array}{l}\text { Finding the error } \\
\text { correctly }\end{array}$} & $\begin{array}{c}\text { Finding the error correctly but no } \\
\text { solution recommendations }\end{array}$ & P7 & 1 \\
\cline { 2 - 4 } & $\begin{array}{c}\text { Finding the error correctly and } \\
\text { recommending a correct solution }\end{array}$ & P5, P10 & 2 \\
\hline \multirow{2}{*}{$\begin{array}{l}\text { Not finding the } \\
\text { error correctly }\end{array}$} & $\begin{array}{c}\text { Finding the error incorrectly and no } \\
\text { solution recommendations }\end{array}$ & P1, P2, P6 & 3 \\
\cline { 2 - 4 } & $\begin{array}{c}\text { Finding the error incorrectly and } \\
\text { recommending an incorrect solution }\end{array}$ & P3, P4, P8, P9 & 4 \\
\hline
\end{tabular}

When the prospective teachers' answers to the first question, asked in relation to the student error "If the perimeter of the rectangle increases, its area also increases" were investigated, the majority of the teachers agreed with the students. When the suggestions given by the prospective teachers who found the error correctly were examined, it was seen that only two of them offered a correct recommendation.

The following direct quote taken from the interview conducted with P10, who spotted the student error accurately and offered an accurate recommendation to correct the error, maybe given as an example to the answers given by the prospective teachers.

"The student's idea that the perimeter of the rectangle increases when its area increases is definitely wrong. The student must have thought that the lengths of the sides also increased. We can show that this is not always the case. Let us consider a rectangle with a width of $4 \mathrm{~cm}$ and a length of $6 \mathrm{~cm}$ and compare it to a rectangle with a length of $13 \mathrm{~cm}$ and a width of $1 \mathrm{~cm}$. The perimeter of the first rectangle is 20 $\mathrm{cm}$, and the perimeter of the second one is 28 , which means that the perimeter has increased. When we look at the areas of these two rectangles, we see that while the area of the first one is $24 \mathrm{~cm}^{2}$, the area of the second one is $13 \mathrm{~cm}^{2}$."

The ideas of P3, who could not detect the error or offer a correct solution to the students, were as follows. 
"I think the way the student thought is right. Let's think of a rectangle with a width of $2 \mathrm{~cm}$ and a length of $4 \mathrm{~cm}$, for example. If the sides of this rectangle increase by 2 $\mathrm{cm}$, the width becomes $4 \mathrm{~cm}$ and the length becomes $6 \mathrm{~cm}$. The perimeter of the first rectangle was $12 \mathrm{~cm}$ but now it is $20 \mathrm{~cm}$, which means that it has increased. While the area of the first one is $8 \mathrm{~cm}^{2}$, that of the second one is $24 \mathrm{~cm}^{2}$. So, as the area increased, the perimeter also increased."

Table 3 shows the code, category, and frequency information of the teachers' answers to the first question.

Table 3. Teachers' Answers to the First Question

\begin{tabular}{|l|c|c|c|}
\hline Category & Code & Teachers & Frequency \\
\hline \multirow{2}{*}{$\begin{array}{l}\text { Finding the error } \\
\text { correctly }\end{array}$} & $\begin{array}{c}\text { Finding the error correctly but } \\
\text { no solution recommendations }\end{array}$ & $\begin{array}{c}\text { T3, T7, T8, T9, } \\
\text { T10 }\end{array}$ & 5 \\
\cline { 2 - 4 } & $\begin{array}{c}\text { Finding the error correctly and } \\
\text { recommending a correct } \\
\text { solution }\end{array}$ & T1, T5 & 2 \\
\hline $\begin{array}{l}\text { Not finding the } \\
\text { error correctly }\end{array}$ & $\begin{array}{c}\text { Finding the error incorrectly } \\
\text { and no solution } \\
\text { recommendations }\end{array}$ & T4 & 1 \\
\cline { 2 - 4 } & $\begin{array}{c}\text { Finding the error incorrectly } \\
\text { and recommending an } \\
\text { incorrect solution }\end{array}$ & T2, T6 & 2 \\
\hline
\end{tabular}

As seen in Table 3, seven of the mathematics teachers found the error correctly while answering the same question. In Table 3, one may see that two of the teachers recommended a correct solution to correct the student's error. These results show that in-service teachers' knowledge of students' understanding of the error was better than the prospective teachers. However, in-service teachers did not possess an adequate level of knowledge of the instructional strategies to offer the right solution.

To illustrate the answers given by the in-service teachers, the answer given by T1, who found the student error correctly and recommended an accurate solution to correct it, maybe quoted as follows.

"The student thought wrong. We can't generalize this situation. Let me show that it can be wrong with an example."

Figure 1. Answer of T1

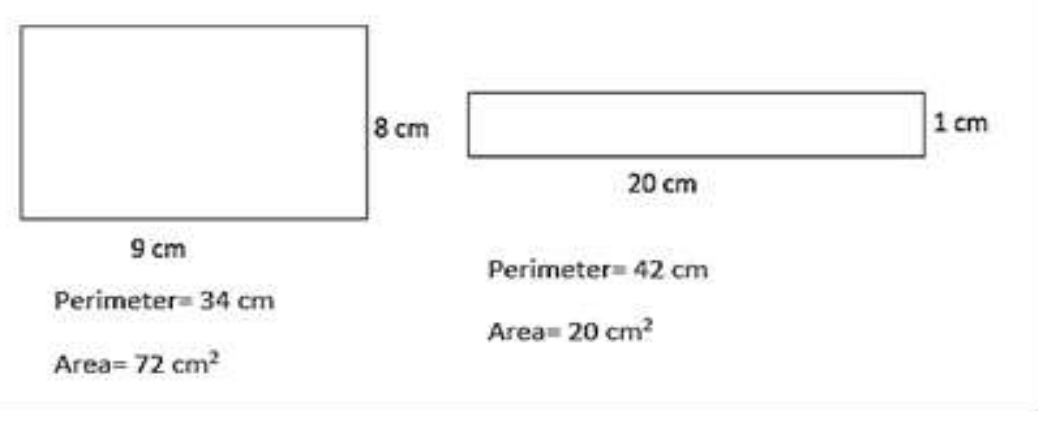


The opinions of T6, who could not find the error correctly or come up with a recommendation for the students, were as follows.

"I also think the student thought rightly, because the area increases when the perimeter increases. Take a rectangle with a width of $4 \mathrm{~cm}$ and a length of $7 \mathrm{~cm}$, for example. Suppose that we have another rectangle with a width of $4 \mathrm{~cm}$ and a length of $10 \mathrm{~cm}$. While the perimeter of the first rectangle is $22 \mathrm{~cm}$, and its area is $28 \mathrm{~cm}^{2}$, the perimeter of the second one is $28 \mathrm{~cm}$, and its area is $40 \mathrm{~cm}^{2}$."

Table 4 shows the code, category and frequency information of the prospective teachers' answers to the second question.

Table 4. Prospective Teachers' Answers to the Second Question

\begin{tabular}{|l|c|c|c|}
\hline Category & Code & Prospective Teachers & Frequency \\
\hline $\begin{array}{l}\text { Finding the error } \\
\text { correctly }\end{array}$ & $\begin{array}{c}\text { Finding the error correctly } \\
\text { and recommending a } \\
\text { correct solution }\end{array}$ & P2, P3, P5, P8, P10 & 5 \\
\hline Not finding the \\
\cline { 2 - 4 } error correctly & $\begin{array}{c}\text { Finding the error } \\
\text { incorrectly and } \\
\text { recommending an incorrect } \\
\text { solution }\end{array}$ & P4, P6, P9 & 3 \\
\hline
\end{tabular}

The prospective teachers had difficulty in understanding the third question and spent a lot of time in forming the parallelogram. Some of them even failed to form one. According to the results obtained in this question, half of the prospective teachers had the knowledge of students' understanding of the error and the knowledge of instructional strategies for making the right solution suggestion were an adequate level.

The response given by P5, who identified the student error correctly and offered an adequate solution, was as follows.

"He thought that when the shapes changed, the sides would decrease, and thus, the perimeter would also decrease, or maybe, he was confused by $\sqrt{5}$ while making the calculations with square root expressions. The first shape is a square and its perimeter is $8 a$. The perimeter of the second shape is, on the other hand, $4 a+2 a \sqrt{5}$. Let's have a look at the range of $\sqrt{5}$. It is closer to 2 , and this makes it more than the perimeter of the square. Here, the child knows that this length is the hypotenuse length, and this is the longest edge."

The response of P1, who identified the student error incorrectly and could not offer a correct recommendation, was as follows. 
“The student's answer is incorrect. We can't make a difference in the length of the shape by adding the cut-up part to other parts of the shape. We can explain it to the student by drawing it."

P4, who had no ideas as to why the student gave a wrong answer, provided the following response.

“...but how will it be possible? We can't place the triangles. The triangles have a right angle. How can I make a parallelogram with them?"

\section{Figure 2. Answer of P5}

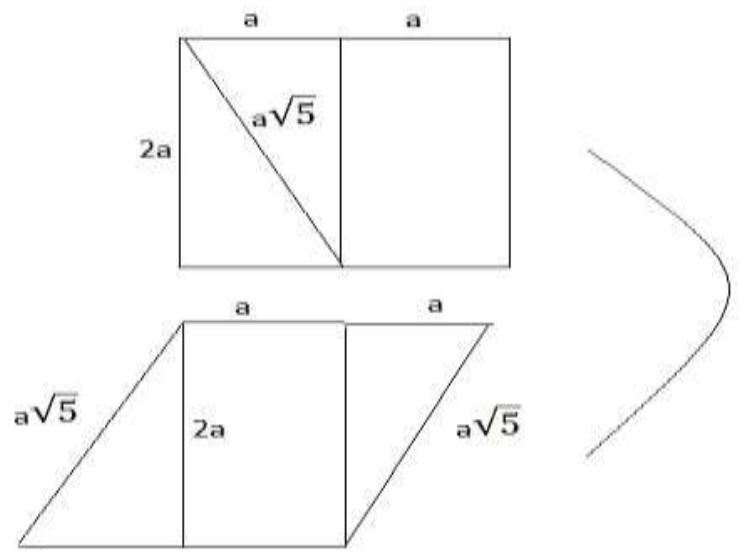

Table 5 shows the code, category, and frequency information of the teachers' answers to the second question.

Table 5. Teachers' Answers to the Second Question

\begin{tabular}{|c|c|c|c|}
\hline Category & Code & Teachers & Frequency \\
\hline \multirow{2}{*}{$\begin{array}{l}\text { Finding the } \\
\text { error correctly }\end{array}$} & $\begin{array}{l}\text { Finding the error correctly but no } \\
\text { solution recommendations }\end{array}$ & $\mathrm{T} 1, \mathrm{~T} 8$ & 2 \\
\hline & $\begin{array}{l}\text { Finding the error correctly and } \\
\text { recommending a correct solution }\end{array}$ & T2, T3, T5, T9, T10 & 5 \\
\hline \multirow{2}{*}{$\begin{array}{l}\text { Not finding } \\
\text { the error } \\
\text { correctly }\end{array}$} & No answer & $\mathrm{T} 7$ & 1 \\
\hline & $\begin{array}{l}\text { Finding the error incorrectly and } \\
\text { recommending an incorrect solution }\end{array}$ & $\mathrm{T} 4, \mathrm{~T} 6$ & 2 \\
\hline
\end{tabular}

When the in-service teachers' answers to the third question were examined, it was clear that seven of the teachers identified the student error correctly, two of them failed to do so, and one of them did not make any comments regarding it. These results showed that most of the in-service teachers had sufficient knowledge of students' understanding in determining the error, but they did not possess an adequate level of knowledge of the instructional strategies 
Vol. 8, No. 4 Deniz Yilmaz \& Kü̈çük Demir: Mathematics Teachers' Pedagogical...

The response of T5, who identified the student error correctly and gave an adequate recommendation, was as follows.

"Let me draw a square whose length is $2 \mathrm{a} \mathrm{cm}$. Its perimeter is $8 \mathrm{a} \mathrm{cm}$. Then let's form the expected shape. It's $8+2 \sqrt{5}$. That is to say, the perimeter has increased."

Figure 3. Answer of T5
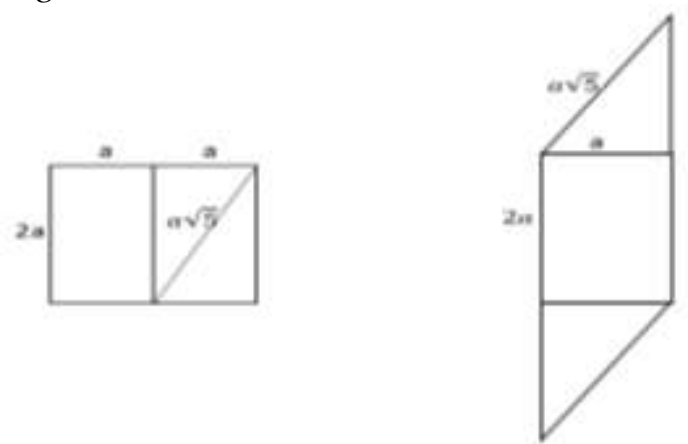

"Here, the student gave the wrong answer. He thought that the shape is narrow. We can show him how it is with the help of the Pythagorean theorem. ...because if the sides are considered as the hypothenuse of the triangle, they have increased, and they became $a \sqrt{5} . "$

T4, who identified the student error incorrectly and could not offer an accurate recommendation, gave the following answer.

"Let me draw it and see."

Figure 4. Answer of T4

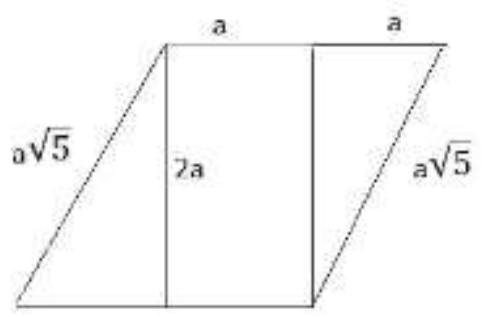

"The perimeter of the parallelogram is less than that of the square."

Table 6 shows the code, category, and frequency information of the prospective teachers' answers to the third question.

In the third question, the results indicate that most of the prospective teachers had sufficient knowledge of students' understanding to identify the error, however half of them had sufficient knowledge of instructional strategies to offer the right solution. 
Table 6. Prospective Teachers' Answers to the Third Question

\begin{tabular}{|c|c|c|c|}
\hline Category & Code & Prospective Teachers & Frequency \\
\hline \multirow{2}{*}{$\begin{array}{l}\text { Finding the } \\
\text { error } \\
\text { correctly }\end{array}$} & $\begin{array}{l}\text { Finding the error correctly but } \\
\text { no solution recommendations }\end{array}$ & P3, P5, P8 & 3 \\
\hline & $\begin{array}{l}\text { Finding the error correctly and } \\
\text { recommending a correct } \\
\text { solution }\end{array}$ & $\mathrm{P} 1, \mathrm{P} 2, \mathrm{P} 4, \mathrm{P} 9, \mathrm{P} 10$ & 5 \\
\hline $\begin{array}{l}\text { Not finding } \\
\text { the error } \\
\text { correctly }\end{array}$ & $\begin{array}{l}\text { Finding the error incorrectly } \\
\text { and recommending an incorrect } \\
\text { solution }\end{array}$ & $\mathrm{P} 6, \mathrm{P} 7$ & 2 \\
\hline
\end{tabular}

The opinions of P10, who spotted the error correctly and offered an accurate recommendation, were as follows.

Figure 5. Answer of P10
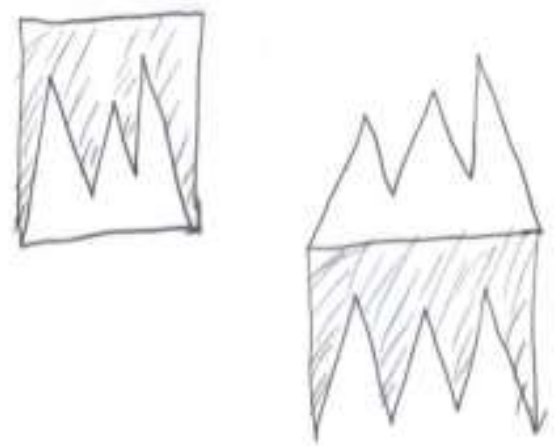

"He made a mistake. He may have thought that there would be more sides. Confusing the area with the perimeter, he thought as if the number of the sides increased, and so did the perimeters. The area doesn't change if the shapes are shifted or placed somewhere else. ... because the area is the surface covered by the shape. As the total area doesn't change, the areas are equal to each other. For instance, when you cover the floor of a rectangular room completely with a carpet, no matter how much you cut it into smaller pieces and place them side by side, the total [area] will definitely not change."

The ideas of P7, who thought the same way as the student and thus identified the student error incorrectly, were as follows.

"I think his answer is right. ... because the second shape covers a larger area. There are zigzags in the second one, so the area of the first shape is smaller."

Based on these explanations, it may be stated that P7 did not know that the area would not change when the shape is shifted or placed somewhere else.

Table 7 shows the code, category, and frequency information of the teachers' answers to the third question. 
Figure 6. Answer of P7

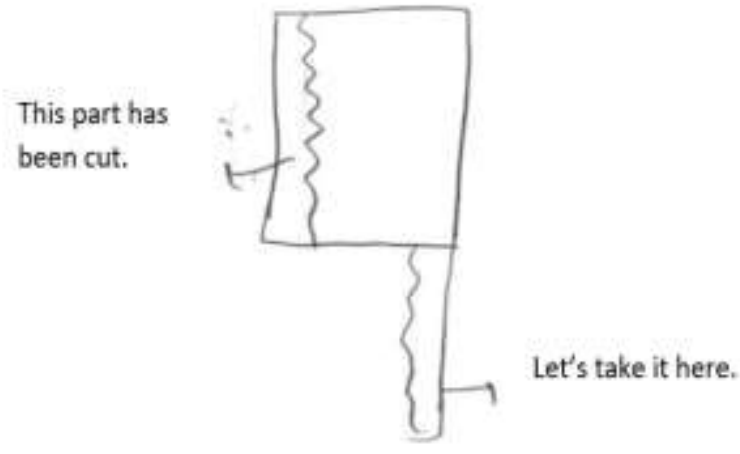

It was observed that the majority of the in-service teachers identified the error correctly, and only one of them did not even do any reasoning related to it. As seen from Table 7, most of the in-service teachers had sufficient knowledge of students' understanding of the error and the knowledge of instructional strategies to suggest the right solution.

Table 7. Teachers' Answers to the Third Question

\begin{tabular}{|c|c|c|c|}
\hline Category & Code & Teachers & Frequency \\
\hline \multirow{2}{*}{$\begin{array}{l}\text { Finding the } \\
\text { error correctly }\end{array}$} & $\begin{array}{l}\text { Finding the error correctly but no } \\
\text { solution recommendations }\end{array}$ & $\mathrm{T} 4, \mathrm{~T} 8$ & 2 \\
\hline & $\begin{array}{l}\text { Finding the error correctly and } \\
\text { recommending a correct solution }\end{array}$ & $\begin{array}{l}\text { T2, T3, T5, T6, } \\
\text { T7, T9, T10 }\end{array}$ & 7 \\
\hline $\begin{array}{l}\text { Not finding the } \\
\text { error correctly }\end{array}$ & No answer & $\mathrm{T} 1$ & 1 \\
\hline
\end{tabular}

The following were the opinions of T10, who spotted the error correctly and recommended an appropriate solution.

"The student thought wrong. The student might have confused the area with the perimeter here. It says zigzag here. Because it is indicated this way, most probably he thought that when the perimeter increases, the area will also increase. Additionally, he thought that the area was larger as there were two more parts. Based on the definition of the area, I try to eliminate the misconception between area and perimeter with concrete examples. For instance, I show the area covered by sugar cubes as a whole, and then, I leave the sugar cubes in a different place. I have the area of each sugar cube calculated. Therefore, the students will notice that the area has not changed."

Lastly, the fourth question will be examined at two stages. First of all, the findings related to how the teachers commented on the change in the perimeters of the two shapes with equal areas (Shapes 1 and 2), and secondly, how they viewed the change in the areas of the two shapes with equal perimeters (Shapes 1 and 3) will be given. 
Table 8 shows the code, category, and frequency information of the prospective teachers' answers to the fourth question with respect to how the perimeters of two shapes with equal areas change.

Table 8. Prospective Teachers' Answers about how the Perimeters of Shapes Change

\begin{tabular}{|c|c|c|c|}
\hline Category & Code & Prospective Teachers & Frequency \\
\hline \multirow{2}{*}{$\begin{array}{l}\text { Finding the } \\
\text { error correctly }\end{array}$} & $\begin{array}{l}\text { Finding the error correctly but } \\
\text { no solution recommendations }\end{array}$ & P5 & 1 \\
\hline & $\begin{array}{l}\text { Finding the error correctly and } \\
\text { recommending a correct } \\
\text { solution }\end{array}$ & P1, P3, P9, P10 & 4 \\
\hline \multirow{2}{*}{$\begin{array}{l}\text { Not finding the } \\
\text { error correctly }\end{array}$} & $\begin{array}{l}\text { Finding the error incorrectly } \\
\text { and no solution } \\
\text { recommendations }\end{array}$ & P8 & 1 \\
\hline & $\begin{array}{l}\text { Finding the error incorrectly } \\
\text { and recommending an incorrect } \\
\text { solution }\end{array}$ & $\mathrm{P} 2, \mathrm{P} 6, \mathrm{P} 7$ & 3 \\
\hline $\begin{array}{l}\text { Finding the } \\
\text { error partially } \\
\text { correctly }\end{array}$ & $\begin{array}{l}\text { Finding the error partially } \\
\text { correctly and recommending an } \\
\text { incorrect solution }\end{array}$ & P4 & 1 \\
\hline
\end{tabular}

When the explanations of the teachers on the student's answer with respect to how the perimeters of two shapes with equal areas (1 and 2) change were considered, half of the prospective teachers had sufficient knowledge of students' understanding in determining the error, and yet more than half had insufficient knowledge of instructional strategies to propose correct solutions.

The ideas of P10, who identified the student error correctly and offered a correct suggestion, were as below.

"The areas of the first and second shapes are equal. The student couldn't figure out how the sides of the parallelogram would change while comparing their perimeters. Probably, he was inclined to find a relevant formula as the length of the vertical edge leg was given as $4 \mathrm{~cm}$, but the lengths of the side legs were not given. The length of the base side was given as $9 \mathrm{~cm}$, and because the lengths of the height and the side legs were not given, the student automatically thought there was missing information. To correct the error, I would emphasize that knowing the side lengths is not essential. I would remind the student that the side lengths of the second shape would be longer than $4 \mathrm{~cm}$ because of the Pythagorean theorem. That is, the perimeter would measure longer."

The following were the views of P6, who failed to identify the student error as she shared the same opinion as to the student and thus offered an incorrect suggestion. 
"In the second shape, the side lengths are not given. Oh no, I can't find the perimeter. I think something is missing. There is missing information in the base length as well... I can't say anything. I guess the student thought right."

The ideas of P4, who identified the error partially correctly but could not recommend a correct solution, were as follows.

"I think the student thought wrong. A triangle is formed in the second shape, and the student could not find a connection between the side of the triangle and the parallelogram. No other information is needed."

Table 9 shows the code, category, and frequency information of the teachers' answers to the fourth question with respect to how the perimeters of two shapes with equal areas change.

Table 9. Teachers' Answers about how the Perimeters of Shapes Change

\begin{tabular}{|l|c|c|c|}
\hline Category & Code & Teachers & Frequency \\
\hline \multirow{2}{*}{$\begin{array}{l}\text { Finding the error } \\
\text { correctly }\end{array}$} & $\begin{array}{c}\text { Finding the error correctly but } \\
\text { no solution recommendations }\end{array}$ & $\mathrm{T} 3$ & 1 \\
\cline { 2 - 4 } & $\begin{array}{c}\text { Finding the error correctly and } \\
\text { recommending a correct } \\
\text { solution }\end{array}$ & T1, T5, T7, T10 & 4 \\
\hline $\begin{array}{l}\text { Not finding the error } \\
\text { correctly }\end{array}$ & $\begin{array}{c}\text { No answer } \\
\text { Finding the error incorrectly } \\
\text { and no solution } \\
\text { recommendations }\end{array}$ & T4, T6, T8 & 3 \\
\hline $\begin{array}{l}\text { Finding the error } \\
\text { partially correctly }\end{array}$ & $\begin{array}{c}\text { Finding the error partially } \\
\text { correctly and no solution } \\
\text { recommendations }\end{array}$ & $\mathrm{T} 9$ & 1 \\
\hline
\end{tabular}

When the explanations of the in-service teachers on the student's answer with respect to how the perimeters of two shapes with equal areas (1 and 2) change were considered, three of the teachers could not make any comments and one of them had the same opinion as the student. These results show that half of the inservice teachers had sufficient knowledge of students' understanding to identify the error, but most of them had insufficient knowledge of instructional strategies to offer correct solutions.

T5, who spotted the student error accurately and offered a correct recommendation, expressed the following opinions.

"He looked at the first and the second shapes. There is no missing information; the student is wrong. I would tell him that, when we compare the first and second shapes, the length of the side edge of the second shape is longer. While doing it, I would also remind him of the hypotenuse. In the second shape, if the vertical edge is $4 \mathrm{~cm}$, because of the property of the hypotenuse, the side edges must be longer than $4 . "$ 
T9, who partially identified the error but could not recommend a correct solution, expressed the following ideas.

"The areas of the first and the second shapes are equal. When we compare their perimeters, we see that the student thought wrong. ...because the lengths of the short sides of the parallelogram are different than those of a rectangle, their perimeters are also not equal to each other."

As it may be seen, even though T9 mentioned the existence of student error, she did not point out what this error stemmed from.

The answer given by $\mathrm{T} 2$, who identified the error in an incorrect way, was as follows.

"The student gave the wrong answer...because the shapes with the same areas are 1 and 2. When their perimeters are taken into account, while the perimeter of the rectangle is 26 , that of the parallelogram is smaller than $26 . "$

In the fourth question, the teachers were also asked to comment on how the areas of two shapes with equal perimeters (Shapes 1 and 3) changed. The findings related to this were as follows.

Table 10 shows the code, category, and frequency information of the prospective teachers' answers to the fourth question with respect to how the areas of two shapes with equal perimeters change.

Table 10. Prospective Teachers' Answers about how the Areas of Shapes Change

\begin{tabular}{|l|c|c|c|}
\hline Category & Code & Prospective Teachers & Frequency \\
\hline \multirow{2}{*}{$\begin{array}{l}\text { Finding the } \\
\text { error } \\
\text { correctly }\end{array}$} & $\begin{array}{c}\text { Finding the error correctly but no } \\
\text { solution recommendations }\end{array}$ & P3 & 1 \\
\cline { 2 - 4 } & $\begin{array}{c}\text { Finding the error correctly and } \\
\text { recommending a correct solution }\end{array}$ & P1, P5, P6, P8, P10 & 5 \\
\hline $\begin{array}{l}\text { Not finding } \\
\text { the error } \\
\text { correctly }\end{array}$ & $\begin{array}{c}\text { Finding the error incorrectly and } \\
\text { recommending an incorrect solution }\end{array}$ & P2, P7, P9 & 3 \\
\hline $\begin{array}{l}\text { Finding the } \\
\text { error partially } \\
\text { correctly }\end{array}$ & $\begin{array}{c}\text { Finding the error partially correctly } \\
\text { and recommending an incorrect } \\
\text { solution }\end{array}$ & P4 & 1 \\
\hline
\end{tabular}

When the prospective teachers' answers to the question related to the student error in finding the areas of shapes with the same perimeters were analyzed, it may be noted that most of the prospective teachers correctly identified the student error and half of them had sufficient knowledge of instructional strategies to suggest the correct solution.

The following was the answer given by P6, who spotted the error correctly and provided a correct recommendation. 
"Now, we see that the perimeters of the first and the third shapes are equal. Here, the student must have thought that he could not calculate the area as the height was not given. ...but if he had drawn a vertical line starting from the corner, he could have found it, indeed. When we form a triangle by taking the vertical edge as the height and the short edge as the hypothenuse, the height is supposed to be smaller than the hypothenuse that is 4 . ... as the area of the third shape will be less than 36 , that is, smaller than the area of the first shape."

The statements of P9, who could not identify the error as he thought the same way as the student, maybe quoted as follows.

"The student will compare one to three. Now, the third shape is a parallelogram, and its base length is $9 \mathrm{~cm}$, but its short edge is $4 \mathrm{~cm}$, and these edges do not intersect vertically. I think the student said it right. ...because the [height of the] first shape and the height of this shape will turn out to be different, and their areas will also be different. ...but as we don't have the necessary information, we can't say anything about it now. Some more information should have been given."

The response given by $\mathrm{P} 4$, who disagreed with the student but still partially identified the error and provided incorrect recommendations, is quoted below.

"The first and third shapes must be dealt with. I think what he said is wrong. First of all, when we look at them, the perimeters [of the first and third shapes] may be equal, but the area will change in parallel with the shape. The reason for this is that the area calculations for shapes such as the square, the rectangle, and the triangle are different."

Table 11 shows the code, category, and frequency information of the teachers' answers to the fourth question with respect to how the areas of two shapes with equal perimeters change.

The findings in Table 11 revealed that half of the in-service teachers had sufficient knowledge of students' understanding to determine the error, but only three of teachers had sufficient knowledge of instructional strategies to offer the right solution. When the findings were analyzed, it was found that the in-service teachers had the most difficulty with the fourth question as not all the side lengths of the parallelogram were given, and neither were the angles or height.

T1, who identified the student error correctly and offered correct recommenddations, stated the following ideas.

"The student wants to be given everything. When he compares the first and the third shapes, he thinks that since the height is not given in the third shape, he cannot calculate the area either. The student was not asked to calculate the area anyway. He was asked to make a comparison. To show it to the student, I would show him that the area of the rectangle is larger. If the short side of the parallelogram is $4 \mathrm{~cm}$, the height of the long side will be less than $4 \mathrm{~cm}$....because there is the hypotenuse." 
Table 11. Teachers' Answers about how the Areas of Shapes Change

\begin{tabular}{|l|c|c|c|}
\hline Category & Code & Teachers & Frequency \\
\hline \multirow{2}{*}{$\begin{array}{l}\text { Finding the } \\
\text { error correctly }\end{array}$} & $\begin{array}{c}\text { Finding the error correctly but no solution } \\
\text { recommendations }\end{array}$ & T3, T4 & 2 \\
\cline { 2 - 4 } & $\begin{array}{c}\text { Finding the error correctly and } \\
\text { recommending a correct solution }\end{array}$ & $\begin{array}{c}\text { T1, T5, } \\
\text { T7 }\end{array}$ & 3 \\
\hline \multirow{2}{*}{$\begin{array}{l}\text { Not finding } \\
\text { the error } \\
\text { correctly }\end{array}$} & $\begin{array}{c}\text { Finding the error incorrectly and no } \\
\text { solution recommendations }\end{array}$ & $\mathrm{T} 2, \mathrm{~T} 10$ & 2 \\
\cline { 2 - 4 } & $\begin{array}{c}\text { Finding the error incorrectly and } \\
\text { recommending an incorrect solution }\end{array}$ & $\mathrm{T} 6$ & 1 \\
\hline $\begin{array}{l}\text { Finding the } \\
\text { error partially } \\
\text { correctly }\end{array}$ & $\begin{array}{c}\text { Finding the error partially correctly and } \\
\text { recommending a partially correct solution }\end{array}$ & $\mathrm{T} 9$ & 1 \\
\hline
\end{tabular}

T6, who wrongly identified the error of the student and offered incorrect recom-menddations, stated the following ideas.

"The perimeters of one and three are equal. When we compare their areas, we see that the student gave a correct answer as the height is unknown in the third shape. Concerning this, even if the height is not given, if the angle had been given, we could have done something."

The ideas of T9, who partially accepted the wrong answer as correct and partially gave a correct recommendation, were as below.

"There is no need for additional information. As the sides of the first and third shapes are equal to each other, their perimeters are equal, as well. ...but as the width of the rectangle and the height which is used in the area calculations of the parallelogram in the third shape are different, their areas will also be different."

\section{Discussion}

This study aimed to investigate the pedagogical content knowledge of student errors in terms of the relationship between area and perimeter in rectangles, squares, and parallelograms by mathematics teachers and prospective mathematics teachers in accordance with the knowledge of students' understanding and instructional strategies. Data analysis revealed that in-service teachers' knowledge of students' understanding of errors and their knowledge of instructional strategies are better than prospective teachers. Findings of this study show that in-service teachers were more capable of detecting students' errors and suggesting the accurate solution than prospective teachers. When analyzed for each question, both in-service teachers and prospective teachers were able to correctly identify 
student errors in the third question about area conservation. Also, the knowledge of instructional strategies by both groups was not sufficient in the first question.

When the responses of the participants on the student misconception as the perimeter of the rectangle increases, its area also increases were analyzed, it was observed that most prospective teachers thought the same way as the student. Although the in-service teachers generally detected the error correctly, some of them were also found to detect the error incorrectly. In their study looking into the misconception that as the perimeter of the rectangle increases, its area also increases, Ma (1999) established that teachers had the same misconception as students. On the other hand, De Sousa, Gusmão, Font, and Lando (2020) found that teachers had some difficulties of understanding different ways to calculate an area. Livy, Muir, and Maher (2012) and Wanner (2019) also found that prospective teachers had the same mistakes as students. When the recommendations of the participants regarding the student error were examined, it was seen that the inservice and prospective teachers made recommendations by giving the rectangular examples where the areas decreased, despite the increase in the perimeters. Consequently, according to the answers given in response to the first question, the in-service mathematics teachers seemed to have more knowledge of students' understanding and instructional strategies than the prospective teachers. As regards this, Menon (1998) also pointed out that the pedagogical content knowledge of prospective teachers developed in time. As Menon put it, prospective teachers can teach certain concepts better, highlight the connections between subjects better and conceive better examples in time.

When a parallelogram was created from a square, it was seen that the inservice teachers perceived it more correctly compared to the prospective teachers in terms of the student error regarding how the perimeter lengths changed. This finding regarding the change in the perimeter lengths was in parallel with that in Tan Şişman and Aksu's study (2009), although their subjects were seventh graders. Their study revealed that seventh graders did not believe that the perimeter of the shape would change when a new shape was formed after it was cut into small pieces and reassembled using the same pieces. In another study parallel to these findings, Jirotková, Vighi, and Zemanová (2019) gave a particular trapezium to 10-11-year-old children and asked to compare areas and perimeters of three geometrical figures created by two trapezia congruent to the first, connected in three different ways. Students aged 10 to 11 thought that these shapes had the same perimeter since these shapes were made up of the same parts. According to Jirotková, Vighi, and Zemanová (2019), the reason of this confusion is related to students visual perception of the area. Instead of deep reasoning, students predominantly visualize the area rather than perimeter and the visualization of perimeter might be eliminated (Jirotková, Vighi, \& Zemanová 2019).

In the third question, the student was asked to form a new shape out of a rectangular sheet after it was cut downwards starting from its long side with zigzags by placing the cut-out part below the rectangle and then to compare the areas of the first and the second shapes. In this case, some prospective teachers stated that they increased the area because the second form took up more space. 
Similar to this result, Baturo and Nason (1996) found that prospective teachers had limited subject matter knowledge, and they were unaware of the fact that even if cut into separate parts, a two-dimensional area of a shape would stay the same when the same parts are reassembled forming a different shape. Here, the prospective teachers confuse the concepts of perimeter and area and the fact that they have misperceptions related to area conservation. In a similar vein, Lee (2009) also examined the views of elementary prospective teachers about the parallelogram area through shearing and squashing processes. In this study, it was also determined that the prospective teachers had the misconception that if the parallelogram perimeter increased, the area also decreased or if the perimeter increased, the area also increased. Although conducted with seventh graders, regarding this, according to Marshall (1997), 7th-grade students had a strong understanding of the concept of perimeter, but their understanding of the concept of area was not well-developed. In his study, he also found that the relationship between area and perimeter could not be understood. Tan Şişman and Aksu's study (2009) also supported these findings in that seventh graders did not have a conception of area conservation.

In the fourth one, the first subject in question was the misconception that the perimeters of the parallelogram and the rectangle cannot be compared when all sides are not known. Some of the prospective teachers thought that, as there were missing sides, nothing could be said about the length of one side of the parallelogram. Some of the in-service teachers, on the other hand, made a mistake in comparing the perimeters as one of the sides of the parallelogram was not given.

The second subject in question four was the misconception that the areas of parallelograms and rectangles whose perimeters are equal cannot be compared since all the side lengths or heights are not known. Some teachers and prospective teachers agreed with the student since the height was not given, a comparison could not be made, as there was missing information. When the obtained data were examined, the fourth question was found as the most difficult by the participant in-service and prospective teachers because of the fact that the angles, all side lengths and height were not given. In her study, to expose prospective teachers' subject matter knowledge, Murphy (2012) asked them to compare the perimeters of shapes with equal areas and the areas of shapes with equal perimeters. Although the two studies were similar in that, in both studies, prospective teachers were found to have difficulty finding the area of the parallelogram, this study was different from the other one as it was also found in this study that the prospective teachers compared the areas and perimeters by placing two shapes on each other. Regarding to this in her study, HerendinéKónya (2015) showed students at the ages of 7-11 two parallelograms with the same lengths but different areas and wanted the students to compare the areas of these parallelograms to the same edges, and it was found that, although it was easy for them to see that the areas were different, the students claimed that the area of these two parallelograms was the same. 


\section{Conclusion}

Overall, when the answers given in response to the interview questions are taken into account, it may be stated that, even though they were on different levels of learning, neither seventh graders nor in-service teachers or prospective teachers had proper conceptual learning. The participants were observed to have the most difficulties in questions related to parallelograms. Marchis (2012) also established in her study that prospective teachers were less successful in tasks related to parallelograms. In this study, the prospective and in-service teachers tended to make a calculation on area and perimeter, but they had hardships explaining the concepts. This situation may have stemmed from the in-service teachers and prospective teachers focusing on computational knowledge rather than conceptual knowledge. Similar to these findings, Menon (1998) and Stemn (2020) conducted to investigate postgraduate and prospective elementary school teachers understanding of perimeter and area in rectangles and triangles and rectangles, also maintained that they had a computational understanding of them rather than a conceptual and relational one. In their studies on the subject matter knowledge of prospective teachers, Berenson et al. (1997), on the other hand, established that many of them had computational knowledge. According to Livy, Muir, and Maher (2012), this computational knowledge limits students' development of conceptual understanding and the potential of instructional strategies.

The results of this study indicate that prospective teachers had less pedagogical content knowledge than the in-service teachers related to area and perimeter. These differences were mostly related to knowledge of students' understanding of errors about area and perimeter. The reasons for these may be that lack of the prospective teachers' experiences or subject matter knowledge. To eliminate these problems, as Setyaningrum, Mahmudi, and Murdanu (2020) stated, students' misconceptions should be exposed more to the teacher training program. In this way, prospective teachers can learn how to spot mistakes of the students and how to identify students' mathematical thoughts during their teacher training programme at undergraduate level; and also have the opportunity to develop pedagogical content knowledge (Runnalls \& Hong, 2019). In this study, in addition to pedagogical content knowledge, it was also observed that prospective teachers were incompetent in required mathematical subject matter knowledge compared to in-service mathematics teachers. In the existing literature, some studies highlight that prospective teachers and in-service teachers have superficial content and pedagogical knowledge about the relationship between area and perimeter. For instance, Livy, Muir, and Maher (2012) noticed that prospective teachers had similar strengths and weaknesses as regards to their subject matter knowledge and pedagogical content knowledge related to area and perimeter, and they stated that prospective teachers had deficiencies in subject matter knowledge, which is necessary for them to understand area and perimeter and make a connection between them. Kurt-Birel, Deniz, and Onel (2020) also found that primary school teachers had only superficial knowledge about area and perimeter of shapes. These researchers claimed that when teachers lacked mathematical subject matter knowledge, they also lacked pedagogical content knowledge and 
that a well-developed pedagogical content knowledge could be obtained with good mathematical subject matter knowledge. Therefore, in future studies, not only pedagogical content knowledge about perimeter and area, but also subject matter knowledge could be investigated.

Although prospective teachers take teaching classes during their undergraduate education, the instructional explanations they made in this study were not sufficient. In this respect, teaching classes may be revised both theoretically and practically to prepare prospective teachers as aimed by the mathematics curriculum. In addition to all this, when perimeter and area are first taught, teachers should teach students what these two concepts are through concrete materials or real-life examples instead of giving them formulae. It is possible to comprehend the perimeter-area relationship by presenting different geometric shapes consisting of the combination of the same number of unit cubes. Another activity recommended for a better understanding of the relationship between area and perimeter is puzzle game known as pentominoes (Wanner, 2019). By including these activities at all levels of education, the relationship between area and perimeter can be easily understood. Moreover, as pointed out by Tan Şişman and Aksu (2009), teachers could help reinforce the understanding of the changes in perimeter and area conservation through activities at school involving cutting, folding, and reassembling. Future studies should examine, in-service teachers' and prospective teachers' pedagogical content knowledge about the relation of area and perimeter of special quadrilaterals other than square, rectangle, and parallelogram can be examined more comprehensively.

\section{References}

Arthur, J., Waring, M., Coe, R., \& Hedges, L.V. (2017). Eğitimde araştırma yöntemleri ve metodolojileri [Research methods and methodologies in education]. Translated by A. Erözkan \& E. Büyüköksüz. Ankara: Anı Yayıncılık.

Baturo, A., \& Nason, R. (1996). Student teachers' subject matter knowledge within the domain of area measurement. Educational Studies in Mathematics, 31(3), 235-268.

Berenson, S., Van Der Valk, T., Oldham, E., Runesson, U., Moreira, C.Q., \& Broekman, H. (1997). An international study to investigate prospective teachers' content knowledge of the area concept. European Journal of Teacher Education, 20(2), 13750.

Chick, H.L., \& Baker, M.K. (2005). Investigating teachers' responses to student misconceptions. In Proceedings of the $29^{\text {th }}$ Conference of the International Group for the Psychology of Mathematics Education (Volume 2, pp. 249-256). Melbourne, Australia.

De Sousa, J.R., Gusmão, T.C.R.S., Font, V., \& Lando, J.C. (2020). Task (re) design to enhance the didactic-mathematical knowledge of teachers. Acta Scientiae, 22(4), 98120.

Gökkurt, B. (2014). Ortaokul matematik öğretmenlerinin geometrik cisimler konusuna ilisskin pedagojik alan bilgilerinin incelenmesi [An examination of secondary school mathematics teachers 'pedagogical content knowledge on geometric shapes]. Unpublished Doctoral Thesis. Erzurum, Turkey: Institute of Educational Sciences, Ataturk University. 
Gökkurt, B., Şahin, Ö., Soylu, Y., \& Soylu, C. (2013). Examining pre-service teachers' pedagogical content knowledge on fractions in terms of students' errors. International Online Journal of Educational Sciences, 5(3), 719-735.

Gökkurt, B., Şahin, Ö., Soylu, Y., \& Doğan, Y. (2015). Pre-service teachers’ pedagogical content knowledge regarding student mistakes on the subject of geometric shapes. Elementary Education Online, 14(1), 55-71.

Guner, P., \& Akyuz, D. (2017). Preservice middle school mathematics teachers' knowledge about students' mathematical thinking related to perimeter and area. The Eurasia Proceedings of Educational and Social Sciences, 6, 61-67.

Herendiné-Kónya, E. (2015). The level of understanding geometric measurement. In CERME9: Proceedings of the $9^{\text {th }}$ Congress of the European Society for Research in Mathematics Education (pp. 536-542). Prague: Faculty of Education, Charles University in Prague and ERME.

Hume, A. (2011). From classroom teacher to teacher educator: generating PCK through action research. Teachers and Curriculum, 12(1), 41-47.

Jirotková, D., Vighi, P., \& Zemanová, R. (2019). Misconceptions about the relationship between perimeter and area. In International Symposium Elementary Mathematics Teaching (pp. 221-231). Prague: Faculty of Education, Charles University in Prague.

Kurt-Birel, G., Deniz, Ş., \& Onel, F. (2020). Analysis of Primary School Teachers' Knowledge of Geometry. International Electronic Journal of Elementary Education, 12(4), 303-309.

Lee, H.S. (2009). Elementary preservice teachers' area conceptions involving the notion of perimeter. In Proceedings of the $31^{\text {st }}$ Annual Meeting of the North American Chapter of the International Group for the Psychology of Mathematics Education (Volume 5, pp. 569-576). Atlanta, GA: Georgia State University.

Livy, S., Muir, T., \& Maher, N. (2012). How do they measure up? Primary pre-service teachers' mathematical knowledge of area and perimeter. Mathematics Teacher Education and Development, 14(2), 91-112.

Ma, L. (1999). Knowing and teaching elementary mathematics. Teachers' understanding of fundamental mathematics in China and the United States. Mahwah, New Jersey: Lawrence Erlbaum Associates, Inc.

Marchis, I. (2012). Pre-service middle school teachers' elementary geometry knowledge, Acta Didactica Napocensia, 5(2), 33-40.

Marshall, L. (1997). Year 7 Students' understanding of the relationship between area and perimeter. Unpublished Master Thesis. Joondalup: Faculty of Education, Edith Cowan University.

Menon, R. (1998). Preservice teachers' understanding of perimeter and area. School Science and Mathematics, 98(7), 361-367.

Murphy, C. (2012). The role of subject knowledge in primary prospective teachers' approaches to teaching the topic of area. Journal of Mathematics Teacher Education, 15(3), 187-206.

Reinke, K.S. (1997). Area and perimeter: pre-service teachers' confusion. School Science and Mathematics, 97(2), 75-77.

Rowland, T., Turner, F., Thwaites, A., \& Huckstep, P. (2009). Developing primary mathematics teaching: reflecting on practice with the knowledge quartet. London: SAGE Publications.

Runnalls, C., \& Hong, D.S. (2019). "Well, they understand the concept of area": preservice teachers' responses to student area misconceptions. Mathematics Education Research Journal, 32(Jul), 629-651.

Setyaningrum, W., Mahmudi, A., \& Murdanu (2020). Pre-service teacher's pedagogical content knowledge: what teachers know about students' errors? In The $3^{\text {rd }}$ 
International Seminar on Innovation in Mathematics and Mathematics Education (ISIMMED 2019). Journal of Physics: Conference Series (Volume 1581, p. 011001). Yogyakarta, Indonesia.

Shulman L. (1986a). Paradigms and research programs in the study of teaching: a contemporary perspective. In M. Wittrock (ed.), Handbook of Research on Teaching. NY: Macmillan Publishing Company.

Shulman, L. (1986b). Those who understand: knowledge growth in teaching. Educational Researcher, 15(2), 4-14.

Shulman, L. (1987). Knowledge and teaching: foundations of the new reform. Harvard Educational Review, 57(1), 1-22.

Stemn, B.S. (2020). Impact of a field-based mathematics methods course on preservice elementary teachers' specialized content knowledge: the case of area and perimeter. Journal of Education \& Social Policy, 7(1), 158-165.

Tan Şişman, G., \& Aksu, M. (2009). Seventh grade students' success on the topics of area and perimeter. Elementary Education Online, 8(1), 243-253.

Tierney, C., Boyd, C., \& Davis, G. (1990). Prospective primary teachers 'conceptions of area. XIV PME, 2, 307-315.

Van de Walle, J.A., Karp, K.S., \& Bay-Williams, J.W. (2014). Ilkokul ve ortaokul matematiği gelişimsel yaklaşımla ögretim [Elementary and middle school mathematics teaching developmentally]. $7^{\text {th }}$ Edition. Translated by S. Durmuş. Ankara: Nobel Yayınları.

Van Driel, J.H., Verloop, N., \& De Vos, W. (1998). Developing science teachers' pedagogical content knowledge. Journal of Research in Science Teaching, 35(6), 673-695.

Van Driel, J.H., Jong, O.D., \& Verloop, N. (2002). The development of preservice chemistry teachers' pedagogical content knowledge. Science Teacher Education, 86(4), 572-590.

Wanner, S.C.A. (2019). Mitigating misconceptions of preservice teachers: the relationship between area and perimeter. Ohio Journal of School Mathematics, 82(1), 36-44.

Yeo, J. (2008). Teaching area and perimeter: mathematics-pedagogical-content knowledge in-action. In M. Goos, R. Brown, \& K. Makar (eds.), Navigating Currents and Charting Directions. (Proceedings of the $31^{\text {st }}$ Annual Conference of the Mathematics Education Research Group of Australasia, pp. 621-627). Brisbane, QLD: MERGA.

Yıldırım, A., \& Şimşek, H. (2013). Sosyal bilimlerde nitel araştırma yöntemleri [Qualitative research methods in the social sciences]. $9^{\text {th }}$ Edition. Ankara: Seçkin Yayıncilik.

Zacharos, K. (2006). Prevailing educational practices for area measurement and students' failure in measuring areas. The Journal of Mathematical Behavior, 25(3), 224-239.

\section{Appendix}

Dear participants,

Please answer the following questions sincerely so that we can figure out your opinions. The length of our interview will be approximately 40 minutes. In this study, your identity will be kept confidential. Thank you for your participation. 


\section{Interview Questions}

1) One of the students said, "If the perimeter of the rectangle increases, its area also increases." Do you think this statement is correct? What would your answer be? Explain.

2) Form two rectangles by cutting a square sheet of paper into two equal parts. Cut one of these rectangles diagonally into two identical parts. Using all of the shapes that you have obtained ( 2 triangles and 1 rectangle), form a parallelogram. How did the area and the perimeter measurements of the first shape and the newly formed shape change? Explain."

In response to this question, one student wrote "The perimeter of the parallelogram is less than that of the square."

Do you think what the student says is right?

Why might this student have thought in this way?

Were you to encounter such a situation, how would you react in response to such an explanation?

3) After cutting a rectangular sheet of paper downwards starting from its long side with zig-zags, form a new shape by placing the cut-out part below the rectangle. How different are the areas of the first shape and the newly formed shape? Explain." In response to this question, one of the students said, "The area of the second shape is bigger than that of the first shape."

Do you think what the student says is right?

Why might this student have thought in this way?

Were you to encounter such a situation, how would you react in response to such an explanation?

4) The students were asked to explain i) how the perimeters of the shapes with identical areas have changed and ii) how the areas of shapes with the same perimeters have changed by looking at these shapes. One of the students said that these shapes could not be compared, for not all of the sides or height measurements are known.

1.

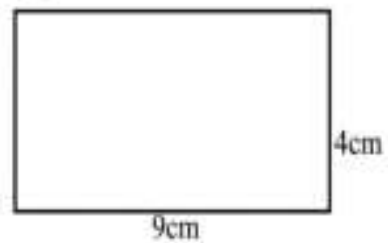

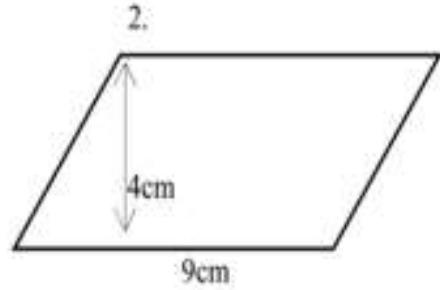

Do you think the way this student thought is correct?

Why might this student have thought in this way?

Were you to encounter such a situation, how would you react in response to such an explanation? 